\title{
Pumilio Binds para mRNA and Requires Nanos and Brat to Regulate Sodium Current in Drosophila Motoneurons
}

\author{
Nara I. Muraro, ${ }^{1}$ Andrew J. Weston, ${ }^{2}$ Andre P. Gerber, ${ }^{3}$ Stefan Luschnig, ${ }^{4}$ Kevin G. Moffat, ${ }^{2}$ and Richard A. Baines ${ }^{1}$ \\ ${ }^{1}$ Faculty of Life Sciences, University of Manchester, Manchester M13 9PT, United Kingdom, ${ }^{2}$ Department of Biological Sciences, University of Warwick, \\ Coventry CV4 7AL, United Kingdom, ${ }^{3}$ Institute of Pharmaceutical Sciences, Department of Chemistry and Applied Biosciences, Eidgenössische Technische \\ Hochschule Zurich, CH-8093 Zurich, Switzerland, and ${ }^{4}$ Institute of Zoology, University of Zurich, CH-8057 Zurich, Switzerland
}

\begin{abstract}
Homeostatic regulation of ionic currents is of paramount importance during periods of synaptic growth or remodeling. Our previous work has identified the translational repressor Pumilio (Pum) as a regulator of sodium current $\left(I_{\mathrm{Na}}\right)$ and excitability in Drosophila motoneurons. In this current study, we show that Pum is able to bind directly the mRNA encoding the Drosophila voltage-gated sodium channel paralytic ( para). We identify a putative binding site for Pum in the $3^{\prime}$ end of the para open reading frame (ORF). Characterization of the mechanism of action of Pum, using whole-cell patch clamp and real-time reverse transcription-PCR, reveals that the full-length protein is required for translational repression of para mRNA. Additionally, the cofactor Nanos is essential for Pum-dependent para repression, whereas the requirement for Brain Tumor (Brat) is cell type specific. Thus, Pum-dependent regulation of $I_{\mathrm{Na}}$ in motoneurons requires both Nanos and Brat, whereas regulation in other neuronal types seemingly requires only Nanos but not Brat. We also show that Pum is able to reduce the level of nanos mRNA and as such identify a potential negative-feedback mechanism to protect neurons from overactivity of Pum. Finally, we show coupling between $I_{\mathrm{Na}}$ (para) and $I_{\mathrm{K}}$ (Shal) such that Pum-mediated change in para results in a compensatory change in Shal. The identification of para as a direct target of Pum represents the first ion channel to be translationally regulated by this repressor and the location of the binding motif is the first example in an ORF rather than in the canonical $3^{\prime}$-untranslated region of target transcripts.
\end{abstract}

Key words: Pumilio; Nanos; Brat; paralytic; aCC; RP2

\section{Introduction}

Neuronal activity is regulated by homeostatic mechanisms that serve to maintain membrane excitability within predefined limits. This is achieved, at least in part, by continual adjustment of both ligand- and voltage-gated ionic conductances to maintain stable action potential firing rates in response to changing synaptic excitation (Turrigiano and Nelson, 2000; Marder and Prinz, 2002; Davis, 2006). Such regulation is predicted to be particularly predominant when neural circuit synaptic activity is changing rapidly, for example during both neuronal circuit development and in the formation of memory (Turrigiano, 1999). However, although now well established, the molecular pathways that underlie homeostatic regulation remain mostly unknown.

Previous studies indicate that activity-dependent regulation of voltage-gated sodium channels is central to the control of membrane excitability in both mammalian and invertebrate neurons (Desai et al., 1999; Baines et al., 2001; Baines, 2003; Mee et

Received Nov. 16, 2007; revised Jan. 10, 2008; accepted Jan. 14, 2008.

This work was supported by The Wellcome Trust United Kingdom (R.A.B.) and a Career Development Award from the International Human Frontier Science Program Organization (A.P.G.). We thank Dr. Wei-Hsiang Lin for construction of a mutated Pum-binding motif. We also thank Kaushiki Menon, Bing Ye, Yuh Nung Jan, and Debora Frank for sharing fly lines.

Correspondence should be addressed to either Nara I. Muraro or Richard A. Baines, Faculty of Life Sciences, Stopford 1.124, University of Manchester, Oxford Road, Manchester M13 9PT, UK. E-mail: nara.muraro@manchester.ac.uk or richard.baines@manchester.ac.uk.

D0I:10.1523/JNEUROSCI.5092-07.2008

Copyright $\odot 2008$ Society for Neuroscience $\quad$ 0270-6474/08/282099-11\$15.00/0 al., 2004). Studies in Drosophila have shown that increased synaptic excitation of motoneurons is countered by a decrease in sodium current $\left(I_{\mathrm{Na}}\right)$ and membrane excitability in these cells (Baines, 2003). Similar, but opposite, changes in $I_{\mathrm{Na}}$ and excitability are observed in mutants that display decreased synaptic excitability (Baines et al., 2001). These changes require the known translational repressor Pumilio (Pum), which we have shown previously is both necessary and sufficient for activity-dependent changes of $I_{\mathrm{Na}}$ in Drosophila motoneurons (Mee et al., 2004). Our model predicts that prolonged change in exposure to synaptic excitation is countered by a reciprocal Pum-dependent regulation in translation of paralytic (para) mRNA and membrane excitability.

The role of Pum is well described from studies of early Drosophila embryogenesis (Barker et al., 1992; Murata and Wharton, 1995; Zamore et al., 1997; Wharton et al., 1998). Specification of the abdomen requires Pum-dependent repression of translation of hunchback $(h b)$ mRNA. The first step begins with the recognition and binding of Pum to the Nanos response element (NRE)motif located in the $3^{\prime}$-untranslated region (UTR) of $h b$ mRNA (Zamore et al., 1997; Wharton et al., 1998). Once bound, Pum then recruits the cofactors Nanos (Sonoda and Wharton, 1999) and Brain Tumor (Brat) (Sonoda and Wharton, 2001) to form a repressor complex that results in the translational repression of $h b$ mRNA. The mechanism of repression involves both deadenylation and poly(A)-independent silencing (Chagnovich and Leh- 
mann, 2001). In addition to its characterized roles in repression of $h b$, Pum has also been shown to bind, and repress translation of, mRNAs encoding the eukaryotic initiation factor $4 E$ (eIF4E) (Menon et al., 2004) and $C y c l i n B(C y c B)$ (Asaoka-Taguchi et al., 1999; Kadyrova et al., 2007). Indeed, these few mRNAs may represent just the tip of the iceberg because the actual list of targets is likely to be extensive based on a recent demonstration that Pum associates with $>1000$ different mRNAs in the ovaries of adult flies (Gerber et al., 2006). Pum proteins are evolutionarily conserved from yeast to mammals (Spassov and Jurecic, 2002; Wickens et al., 2002), and, moreover, Pum expression is activity dependent in mammalian neurons in culture (Vessey et al., 2006).

In this study, we report that Pum is able to directly bind para mRNA (encoding the Drosophila voltage-gated $\mathrm{Na}^{+}$channel). The mechanism of para translational repression shows similarities and differences to Pum-dependent repression of $h b$ mRNA. We show that, unlike repression of $h b$, full-length Pum is necessary for para repression. As for most other Pum-dependent repressed transcripts described to date, para repression requires the presence of the cofactor Nanos. However, the requirement for the cofactor Brat is neuronal type specific. We also show that Pum is sufficient to downregulate nanos mRNA levels in the CNS, a property that may serve to protect neurons from the effects of overactivity of this translational repressor.

\section{Materials and Methods}

Fly stocks. Flies were maintained on apple juice agar plates supplemented with live yeast paste at $25^{\circ} \mathrm{C}$. Wild type was Canton-S (CS). Tissuespecific expression of transgenes in the nervous system was achieved using the GAL4/UAS system (Brand and Perrimon, 1993). RN2-O-GAL4 (homozygous viable on the second chromosome) or RN2-E-GAL4 (homozygous viable on the third chromosome) were used to express UAS transgenes in aCC/RP2 motoneurons (Fujioka et al., 1999; Baines, 2003). These are identical transgenes inserted on different chromosomes. For real-time PCR experiments, 1407-GAL4 (homozygous viable on the second chromosome) was used to express transgenes in all CNS neurons. UAS-pum full-length (homozygous viable on the second chromosome) (Schweers et al., 2002), UAS-pum ${ }^{\mathrm{RBD}}$ (homozygous viable on the second chromosome) (Menon et al., 2004), UAS-pum ${ }^{\text {RBD-V5 }}$ (homozygous viable on the third chromosome), UAS-Pum ${ }^{\text {G1330D }}$ (homozygous viable on the second chromosome) (Ye et al., 2004), and UAS-nanos (homozygous viable on second chromosome) (Ye et al., 2004) have been described previously. UAS-brat (on the second chromosome, rebalanced over $\mathrm{CyO}^{\mathrm{GFP}}$ for this work) is described by Frank et al. (2002). nanos ${ }^{17}$ was provided by the Bloomington Stock Centre and rebalanced over TM3 ${ }^{\text {SerGFP }}$. para was removed using a small deficiency [Df(1) D34] (Baines and Bate, 1998) and rebalanced over FM7 GFP.

TAP-Pum ${ }^{R B D}$ pull-down assays. Five grams of elaV-GAL4; UAS-TAPpum $^{\text {RBD }}$ or elaV-GAL4; + mock control flies were collected 1-3 d after eclosure. Flies were frozen in liquid nitrogen and TAP-Pum ${ }^{\mathrm{RBD}}$ was affinity-purified from extracts as previously described (Gerber et al., 2006). For reverse transcription (RT)-PCR, $1 \mu \mathrm{g}$ and $100 \mathrm{ng}$ of total RNA isolated from extracts and from tobacco etch virus (TEV) protease eluates, respectively, were mixed with oligo-dT $\left[\mathrm{dNV}(\mathrm{T})_{22}\right]$ and random nonamer primers $(5 \mu \mathrm{g}$ each) and made up to $15 \mu \mathrm{l}$ with RNase-free water. The mix was incubated at $70^{\circ} \mathrm{C}$ for $10 \mathrm{~min}$ followed by incubation on ice. First-strand buffer (Invitrogen, Carlsbad, CA) (15 $\mu$ l) was supplemented with $0.5 \mathrm{~mm}$ deoxyribonucleoside triphosphates (dNTPs) and $20 \mathrm{U}$ of RNaseOUT (Invitrogen) was added to the mixture. A fraction, 10 $\mu \mathrm{l}$, was transferred into a second tube ( $-\mathrm{RT}$ control) and $1 \mu \mathrm{l}(100 \mathrm{U})$ of Superscript RT II (Invitrogen) was added to the remaining $20 \mu \mathrm{l}$. Samples were incubated for $2 \mathrm{~h}$ at $42^{\circ} \mathrm{C}, 5 \mathrm{~min}$ at $95^{\circ} \mathrm{C}$, and put on ice. PCR was conducted with $1.5 \mu \mathrm{l}$ of the RT reaction with oligo pairs paraT7Fw1 (5'-TAATACGACTCACTATAGGGCACCCAGTACATACGCTATG-3', which bears sequences for the T7 promotor at the $5^{\prime}$ end) and para-Rev1 (5' -CAGACATCCGCCGTGCGCGACGTG-3') for amplifi- cation of para transcripts, and gfat2F (5'-CTCCTCGCAGATTAGGATCG-3') and gfat2R (5'-AAGGCCTACACCTCCCAGTT-3') to amplify glutamine-fructose-6-phosphate aminotransferase 2 (gfat2) transcripts. PCR was performed for $2 \mathrm{~min}$ at $94^{\circ} \mathrm{C}, 28$ cycles at $94^{\circ} \mathrm{C}$ for $30 \mathrm{~s}, 53^{\circ} \mathrm{C}$ for $30 \mathrm{~s}, 72^{\circ} \mathrm{C}$ for $1 \mathrm{~min}$, and $2 \mathrm{~min}$ at $72^{\circ} \mathrm{C}$. To amplify gfat 2 , annealing was done at $58^{\circ} \mathrm{C}$.

Pull-down experiments with biotinylated RNAs. Synthesis of biotinylated transcripts and pull-down assay were performed as described with minor modifications (Gerber et al., 2006). para was amplified by PCR from $100 \mathrm{ng}$ of Drosophila genomic DNA with primer pairs para-T7Fw1 and para-Rev1. A total of 4 pmol of biotinylated RNA was mixed with 200 $\mu l$ of extract $\left(\mathrm{OD}_{280}, 25\right)$ prepared from elaV-GAL4; UAS-TAP-pum ${ }^{\mathrm{RBD}}$ adult flies.

Embryo and larvae dissection. Newly hatched larvae or late-stage 17 (19-21 h after egg laying at $25^{\circ} \mathrm{C}$ ) embryos were dissected, and central neurons were accessed for electrophysiology as described by Baines and Bate (1998). Late-stage 17 embryos were first dechorionated using 50\% bleach for $2 \mathrm{~min}$, and the vitelline membrane was then manually removed using sharp tungsten wires. The larva/embryo was visualized using a water immersion lens (total magnification, $600 \times$ ) combined with Normarski optics (BX51W1 microscope; Olympus Optical, Tokyo, Japan).

Electrophysiology. Recordings were performed in young first instar larvae, 1-4 h after hatching, or late-stage 17 embryos (in the case of nonviable genotype) at room temperature $\left(22-24^{\circ} \mathrm{C}\right)$. Whole-cell voltageclamp recordings were done using thick-walled borosilicate glass electrodes (GC100F-10; Harvard Apparatus, Edenbridge, UK), fire polished to resistances of between 15 and $20 \mathrm{M} \Omega$. Cells were initially identified based on both size and dorsal position in the ventral nerve cord. Unequivocal identification was determined after recording by labeling with $0.1 \%$ Alexa Fluor 488 hydrazyde, sodium salt (Invitrogen), which was included in the patch saline. Recordings were made using a Multiclamp 700B amplifier controlled by pClamp 9.2 (Molecular Devices, Sunnyvale, CA). Only cells with input resistance $>1$ G $\Omega$ were accepted for analysis. To better resolve $I_{\mathrm{Na}}$, an on-line leak subtraction protocol was used $(\mathrm{P} / 4)$. Currents shown are the average of three trials for $I_{\mathrm{Na}}$ and five trials for $I_{\mathrm{K}}$. Currents shown were normalized for cell capacitance. To determine the effect of gene expression on electrical properties, we analyzed the peak current for each ion $\left(I_{\mathrm{Na}}\right.$ at $-20 \mathrm{mV}, I_{\mathrm{Kfast}}$ and $I_{\mathrm{Kslow}}$ at $+45 \mathrm{mV}$, and $I_{\mathrm{Ba}(\mathrm{Ca})}$ at $-10 \mathrm{mV}$ ).

Solutions. Saline for dissection consisted of the following (in mM): 135 $\mathrm{NaCl}, 5 \mathrm{KCl}, 4 \mathrm{MgCl}_{2} \cdot 6 \mathrm{H}_{2} \mathrm{O}, 2 \mathrm{CaCl}_{2} \cdot 2 \mathrm{H}_{2} \mathrm{O}, 5 \mathrm{~N}$-Tris(hydroxymethyl)methyl-2-aminoethanesulfonic acid (TES), and 36 sucrose, $\mathrm{pH}$ 7.15. For isolation of $I_{\mathrm{Na}}$, the following solution was used (in $\mathrm{mM}$ ): 100 $\mathrm{NaCl}, 6 \mathrm{KCl}, 2 \mathrm{MgCl}_{2} \cdot 6 \mathrm{H}_{2} \mathrm{O}, 2$ sucrose, 50 tetraethylammonium chloride (TEA), 104 -aminopyridine (4-AP), and 10 HEPES, pH 7.1. For isolation of $I_{\mathrm{K}}$, the following solution was used (in $\mathrm{mm}$ ): $135 \mathrm{NaCl}, 5 \mathrm{KCl}, 4$ $\mathrm{MgCl}_{2} \cdot 6 \mathrm{H}_{2} \mathrm{O}, 2 \mathrm{CaCl}_{2} \cdot 2 \mathrm{H}_{2} \mathrm{O}, 5$ TES, 36 sucrose, and $10^{-6}$ tetrodotoxin (TTX) (Alomone Labs, Jerusalem, Israel), $\mathrm{pH}$ 7.1. For isolation of $I_{\mathrm{Ba}(\mathrm{Ca})}$, the following solution was used (in $\mathrm{mm}$ ): $50 \mathrm{NaCl}, 6 \mathrm{KCl}, 50 \mathrm{BaCl}, 10$ $\mathrm{MgCl}_{2} \cdot 6 \mathrm{H}_{2} \mathrm{O}, 10$ glucose, 50 TEA, 10 HEPES, and $10^{-6}$ TTX, pH 7.1. Internal patch solution was as follows (in $\mathrm{mM}$ ): $140 \mathrm{~K}^{+}$methylsulfonate $\left(\mathrm{KCH}_{3} \mathrm{SO}_{3}\right), 2 \mathrm{MgCl}_{2} \cdot 6 \mathrm{H}_{2} \mathrm{O}, 2 \mathrm{EGTA}, 2 \mathrm{KCl}$, and 20 HEPES, pH 7.4. When recording $I_{\mathrm{Na}}$ or $I_{\mathrm{Ba}(\mathrm{Ca})}, \mathrm{CsCl}_{2}$ was substituted for $\mathrm{KCH}_{3} \mathrm{SO}_{3}$.

Real-time PCR. RNA was extracted from whole late-stage 17 embryos or first instar larvae ( para) or from isolated CNSs from these stages (Shal, slo, nanos, $\mathrm{DmCa} 1 \mathrm{~A}$, and pum mRNA detection) using a Qiagen RNeasy Mini kit (Qiagen, Crawley, UK). Briefly, 35 late-stage 17 embryos or first instar larvae (or their isolated CNSs) were homogenized with a plastic mortar followed by repeated passage through a 20-gauge needle in $350 \mu \mathrm{l}$ of lysis buffer containing $0.1 \mathrm{~m} \beta$-mercaptoethanol. The lysate was then centrifuged, $1 \mathrm{vol}$ of $70 \%$ ethanol added and passed through an RNeasy column. After washing in buffer, immobilized nucleic acids were then treated with $\sim 190 \mathrm{U}$ of DNase I for $15 \mathrm{~min}$, washed again in stages according to manufacturer's protocol, and then eluted in $\sim 35 \mu \mathrm{l}$ of RNase-free water. Quantification of RNA concentration in eluates was made using a ND-1000 Nanodrop spectrophotometer (Nanodrop, Wilmington, DE).

Synthesis of cDNA was performed following the protocol in RevertAid 
First Strand cDNA Synthesis kit (Fermentas, York, UK). RNA (concentration $\geq 1.25 \mathrm{ng} / \mu \mathrm{l})$ was mixed with $0.2 \mu \mathrm{g}(1 \mu \mathrm{l})$ random hexamer primers (Fermentas) and made up to $11 \mu \mathrm{l}$ with RNase-free water. The mix was incubated at $65^{\circ} \mathrm{C}$ for 5 min to denature RNA followed by incubation on ice for $1 \mathrm{~min}$. A total of $4 \mu \mathrm{l}$ of reaction buffer (in mM: 250 Tris- $\left.\mathrm{HCl}, 250 \mathrm{KCl}, 20 \mathrm{MgCl}_{2}, 50 \mathrm{DTT}\right), 2 \mu \mathrm{l}$ of $10 \mathrm{~mm}$ dNTPs, and $1 \mu \mathrm{lof}$ Ribolock ribonuclease inhibitor (Fermentas) were added, and the mix was incubated at $25^{\circ} \mathrm{C}$ for $5 \mathrm{~min}$. Then, after addition of $1 \mu$ l of RevertAid $\mathrm{M}-\mathrm{MuLV}$ (monkey murine leukemia virus) reverse transcriptase (Fermentas), the reaction was subsequently incubated for $10 \mathrm{~min}$ at $25^{\circ} \mathrm{C}, 60$ $\min$ at $42^{\circ} \mathrm{C}$, and $15 \mathrm{~min}$ at $65^{\circ} \mathrm{C}$. From the total reaction volume of $20 \mu \mathrm{l}$, $1 \mu \mathrm{l}$ of cDNA was used for each PCR.

Clone Manager software (Sci-Ed, Cary, NC) was used to design primers for para, pum, nanos, slo, Shal, DmCa1A, and ribosomal protein 49 (rp49), a housekeeping gene. All primers are shown in $5^{\prime}$ to $3^{\prime}$ orientation: $r p 49$ forward and reverse primers, CACCGGAAACTCAATGGATACTG and TTCTTCACGATCTTGGGCC; para forward and reverse primers, GATCTATATGGGCGTGCTCACGCAGAAGTG and TGCAGGCACACGTAATCGTCGTCGCATTG; pum forward and reverse primers, CGGCCCAACAGAATCTCTACTC and GCGGCGACCCGTCAA; nanos forward and reverse primers, CAATGGCGGCAACTTAATG and CCACACGTTGTTCAGATG; slo forward and reverse primers, CTTAACACACAAGGAAAAATTTCGTGG and GTGTTCGTTCTTTTGAATTTGAATTGG; Shal forward and reverse primers, ATGGCCAACGTGGTGGAGACGGTGCCGTGTGG and TTCGCTGGCGCAGGACTTGAGCGTGTAGCC; DmCalA forward and reverse primers, TGTACTGCCATCTCCAGTTC and GTGCGTATCTTGGTGTTGTC; respectively.

A Roche Lightcycler 1.5 was used to undertake relative quantification of target mRNAs. Reactions contained $5 \mu \mathrm{l}$ of Mastermix ( $3 \mathrm{mM} \mathrm{MgCl}_{2}$, Taq polymerase, dNTPs; Biogene, Kimbolton, UK), $0.5 \mu \mathrm{l}$ of each forward and reverse primer (both $10 \mathrm{~mm}$ ), $2 \mu \mathrm{l}$ of water, and $1 \mu \mathrm{l}$ of 1:1000 dilution SYBR Green (Invitrogen) and $1 \mu \mathrm{l}$ of cDNA. Cycling was as follows: initial denaturation of $10 \mathrm{~s}$ at $94^{\circ} \mathrm{C}$, and then 35 cycles of $5 \mathrm{~s}$ annealing at $54^{\circ} \mathrm{C}$ for para, $65^{\circ} \mathrm{C}$ for Shal, $60^{\circ} \mathrm{C}$ for slo, and $57^{\circ} \mathrm{C}$ for all the other primer pairs used (determination of $r p 49$ was performed at either temperature), extension at $72^{\circ} \mathrm{C}$ for 10 or $20 \mathrm{~s}$ (for amplicons of $<250$ or $>250 \mathrm{nt}$, respectively), and denaturation at $94^{\circ} \mathrm{C}$. Reactions were performed in triplicate. Fluorescence was acquired at the end of each elongation step using the F1 detection channel with a gain of 1 . Authenticity of PCR products was verified by melting-curve analysis and comparison with melting curves for a nontemplate control for each primer pair used. mRNA levels are expressed as relative fold change normalized against rp49 mRNA. The comparative cycle threshold (Ct) method (User Bulletin 2, 1997; Applied Biosystems, Foster City, CA) was used to analyze the data by generating relative values of the amount of target cDNA (Mee et al., 2004).

Statistics. Statistical significance between control and experimental groups was calculated using a nonpaired $t$ test with a confidence interval of ${ }^{\star} p \leq 0.05$ or ${ }^{* *} p \leq 0.01$.

\section{Results}

\section{Pumilio binds para mRNA}

Our previous work has shown that increased expression of Pum is able to downregulate the mRNA of para and reduce the peak amplitude voltage-gated $I_{\mathrm{Na}}$ in identified motoneurons aCC/RP2 (Mee et al., 2004). However, no evidence for binding between Pum and para mRNA has been demonstrated. To directly test whether Pum associates with para mRNA in the Drosophila nervous system, we generated transgenic flies that express a tandemaffinity purification (TAP)-tagged RNA binding domain (RBD) of Pum (Gerber et al., 2006) specifically in neuronal cells using the GAL4/UAS system. Tagged Pum ${ }^{\text {RBD }}$ was then recovered from adult fly extracts by affinity selection on IgG beads and subsequent cleavage with TEV protease as previously described (Gerber et al., 2006). As a control, the same procedure was performed in parallel with flies not expressing the tagged Pum ${ }^{\mathrm{RBD}}$ construct
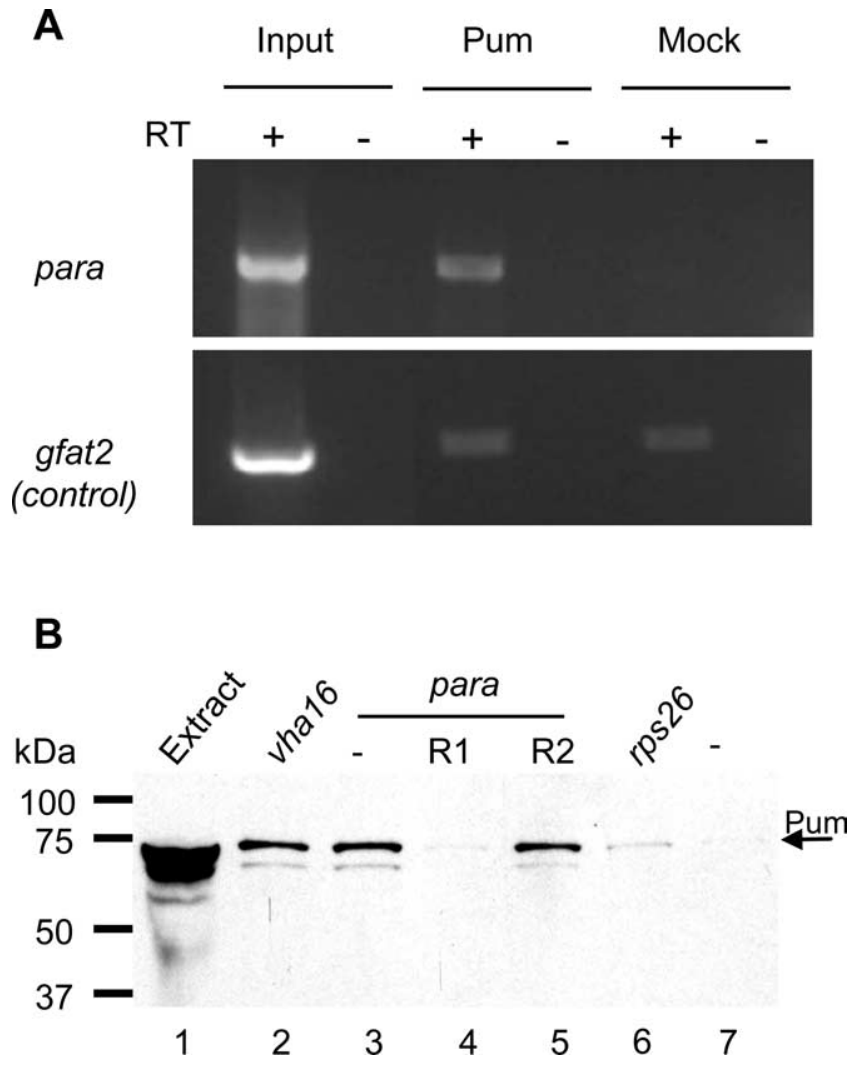

Figure 1. TAP-Pum ${ }^{\mathrm{RBD}}$ specifically associates with para transcripts. $\boldsymbol{A}$, para transcript was detected by RT-PCR in total RNA isolated from fly extracts (input) and from elaV:TAP-Pum ${ }^{\text {RBD }}$ affinity isolations (Pum). In comparison, no detectable para was amplified from the mock control. Loading control was gfat2. Control reactions without RT ( - ) are shown next to samples performed with RT (+). $\boldsymbol{B}$, RNA-protein complexes of biotin-labeled RNA and Drosophila extracts expressing UAS-TAP-pum ${ }^{\mathrm{RBD}}$ monitored for the presence of TAP-Pum ${ }^{\mathrm{RBD}}$ by immunoblot analysis. Lane 1, Input (Drosophila extract); lane 2, 3'-UTR sequence of Vha16; lanes 3-5, a fragment of para encompassing parts of the ORF (lane 3 ) combined with 100-fold excess of competitor RNA (R1; AUUGUAAAUA; lane 4) or control RNA (R2; AUACAAAAUA; lane 5). rps 26 $3^{\prime}$-UTR is the negative control probe RNA (lane 6). No RNA was added in lane 7.

(mock control). Microarray analysis of the associated RNAs revealed significant association of para mRNA in elaV:Pum ${ }^{\text {RBD }}$ versus mock controls (A. Gerber and S. Luschnig, unpublished data). To further substantiate these results, we performed RTPCR on RNA from the affinity isolates. The para transcript was detected in RNA isolated from affinity-purified material of TAP Pum ${ }^{\text {RBD }}$ expressing flies but was not detectable in RNA isolated from mock controls (Fig. $1 \mathrm{~A}$ ). In contrast, no particular enrichment was seen for the messages coding for gfat2 (glutaminefructose-6-phosphate aminotransferase 2) or actin (act5), both of which are abundant messages that are not predicted to be Pum targets (Fig. 1A) (data not shown). Thus, together, the microarray and RT-PCR data show that para mRNA associates with Pum in neurons.

To determine the location of potential Pum-binding sites in the para transcript, a bioinformatic search was undertaken using a consensus core $8 \mathrm{nt}$ motif (UGUAAAUA) previously identified from an analysis of Pum-bound transcripts from ovaries (Gerber et al., 2006). This search revealed one exact match in the open reading frame (ORF) of para (chromosome coordinates X: $16358030,16358037)$. To test whether this sequence was sufficient to bind Pum, a region encompassing this motif (chromosome coordinates X: 16357822, 16358541) was used in RNA pulldown experiments using synthetic biotinylated transcripts added 
to Drosophila extracts expressing TAPPum $^{\text {RBD }}$ (Fig. 1B). Similar to a positive control RNA encoding a fragment of Vha16 3'-UTR, previously shown to bind to Pum ${ }^{\text {RBD }}$ (Gerber et al., 2006), this region of para mRNA was able to bind to Pum ${ }^{\text {RBD }}$ (Fig. 1B, lanes 2 and 3). Moreover, this binding was specifically competed by the addition of excess of a $10 \mathrm{nt}$ RNA fragment comprising the Pumbinding consensus sequence (Fig. $1 B$, lane 4) but not with a control RNA where the conserved core UGU was mutated to ACA (Fig. 1B, lane 5). Finally, mutation of the Pum-binding consensus sequence in the para transcript (cGUcAAUA) is sufficient to abolish binding of Pum (data not shown). These results not only corroborate our previous binding observations gained from microarray and PCR but, additionally, show that a region within the para ORF is sufficient to bind Pum.

Full-length Pumilio is necessary for repression of para

The Pum ${ }^{\text {RBD }}$ consists of eight imperfect repeats that mediate the binding of the target mRNA and the cofactor Nanos to produce a translation repressor complex (Sonoda and Wharton, 1999). A high degree of conservation of the RBD has been described in proteins of the Pum family from yeast to humans (Zamore et al., 1997). Expression of only the Pum ${ }^{\text {RBD }}$ has been reported to be sufficient for a partial rescue of the pum mutant embryonic abdominal segmentation phenotype resulting from the lack of Pum-mediated $h b$ mRNA repression (Wharton et al., 1998). However, the portion of Pum protein relevant to CNS-related processes remains controversial. On the one hand, Pum ${ }^{R B D}$ is sufficient to mimic the dendrite branching phenotype resulting from full-length Pum expression in dendritic arborization neurons (Ye et al., 2004). In contrast, fulllength Pum is required to rescue the neuromuscular junction defects seen in pum mutants (Menon et al., 2004). Given this controversy, we investigated whether overexpression of the Pum ${ }^{\mathrm{RBD}}$ on its own was sufficient to repress para mRNA and $I_{\mathrm{Na}}$ in central neurons. To do this, we overexpressed UAS-pum ${ }^{\mathrm{RBD}}$, a construct containing only the RBD of Pum. We also tested UAS-pum ${ }^{\text {RBD-V5 }}$ and UAS-TAPpum ${ }^{\mathrm{RBD}}$, independent constructs also bearing only the pum ${ }^{\mathrm{RBD}}$. Overexpression of these constructs was tested for their ability to downregulate both $I_{\mathrm{Na}}$ in identified motoneurons and para mRNA in whole CNS. Figure 2, $A-C$, shows that only full-length Pum is able to repress $I_{\mathrm{Na}}$ in

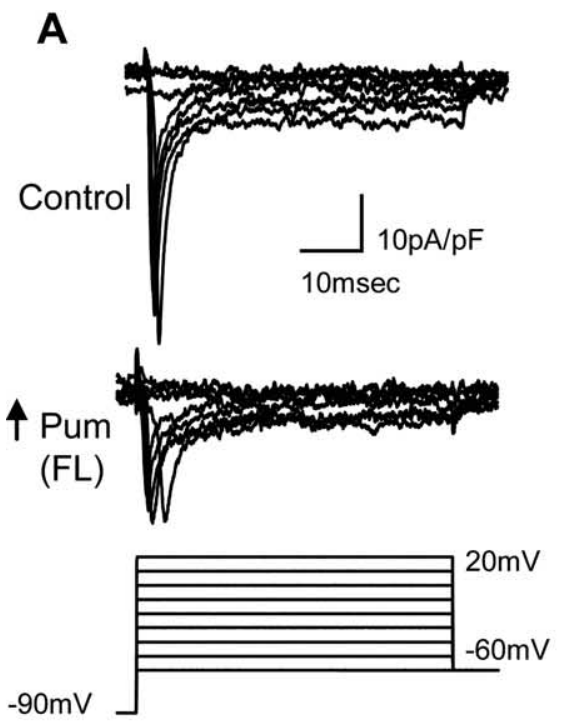

C
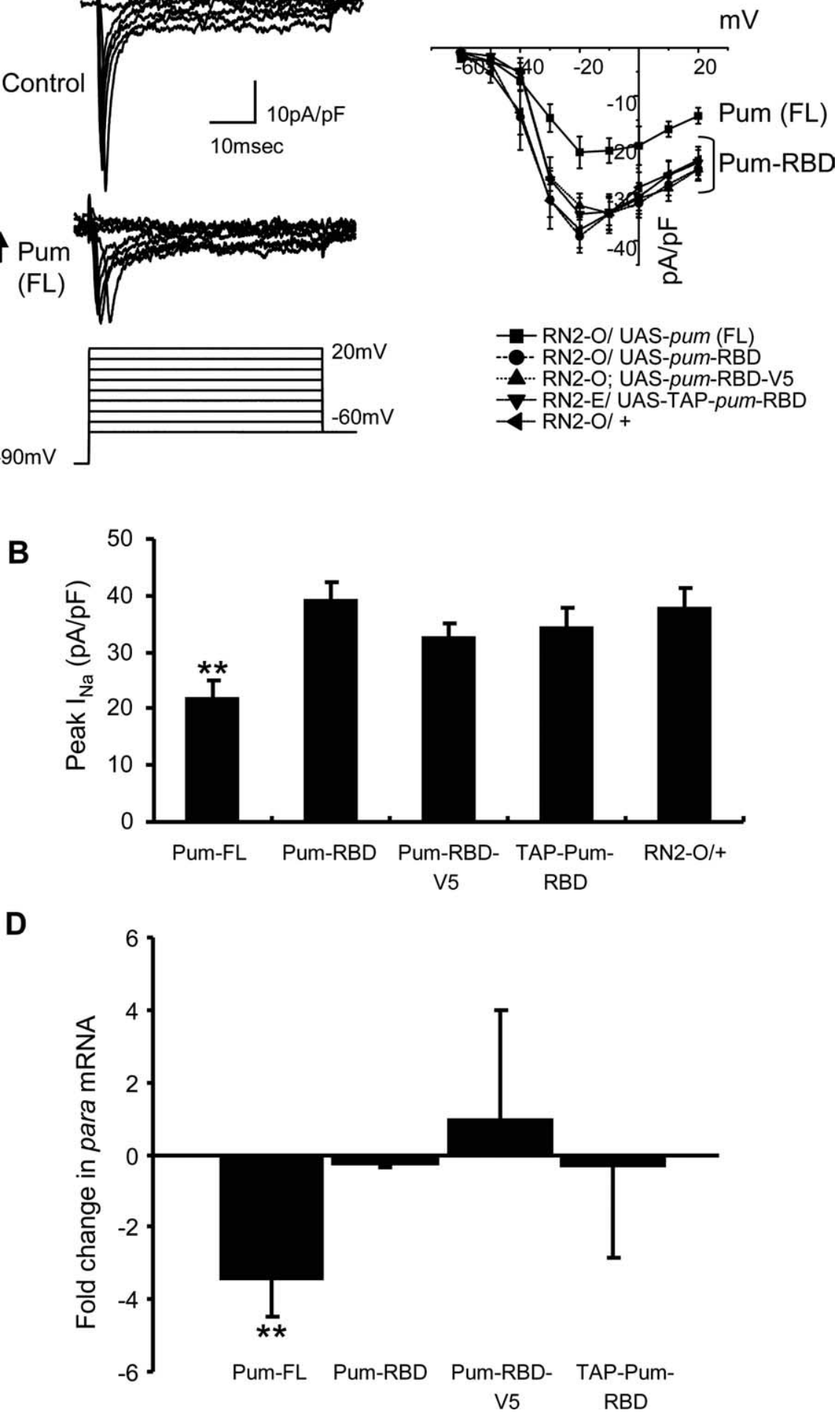

Figure 2. Full-length Pumilio is required for repression of voltage-gated $I_{\mathrm{Na}}$ and para mRNA. $A$, Representative voltage-clamp recordings of voltage-gated $I_{\mathrm{Na}}$ in aCC/RP2 motoneurons of control (RN2-0-GAL4/+; top trace) and increased pum expression (UAS-pum/RN2-0-GAL4; middle trace). The voltage protocol used is shown (bottom trace). B, Peak current amplitudes (measured at $-20 \mathrm{mV}$ ) show that only Pum (FL) is sufficient to significantly decrease in $I_{\mathrm{Na}}(p=0.004)$ compared with RN2-0-GAL4/+ control. Values shown are as follows: $21.7 \pm 3.3,39.1 \pm 3.4,32.7 \pm 2.4,34.4 \pm 3.3$, and $37.7 \pm 3.7$, respectively. C, Current-voltage plots for $I_{\mathrm{Na}}$ measured after overexpression of UAS-pum FL or pum-RBD constructs (UAS-pum ${ }^{\mathrm{RBD}}$, UASpum $^{\mathrm{RBD}-\mathrm{V} 5}$, UAS-TAP-pum ${ }^{\mathrm{RBD}}$ ). D, Real time RT-P(R quantification of para mRNA shows that Pum ${ }^{\mathrm{RBD}}$ is not sufficient to downregulate para mRNA. Levels of para mRNA were compared with the driver control (1407-GAL4). Only Pum (FL) produces a significant reduction ( $p=0.003$ ) of para mRNA. Values shown are as follows: $-3.47 \pm 0.98,-0.22 \pm 0.14,0.93 \pm 3.1$, and $-0.22 \pm 2.56$, respectively. For $\boldsymbol{B}$ and $\boldsymbol{C}$, values given are means $\pm \operatorname{SE}(n \geq 8)$. For $\boldsymbol{D}$, values given are means $\pm \operatorname{SE}(n \geq 4) .{ }^{* *} p$ $\leq 0.001$. 
aCC/RP2. Real-time RT-PCR quantification of para mRNA similarly shows that only full-length Pum is able to downregulate para mRNA in whole CNS (Fig. $2 D$ ). These results suggest that the translational repression mechanism of para mRNA requires the participation of parts of the Pum protein outside the RBD. This represents a clear difference between the mechanism of repression of the para transcript compared with the known mechanism of repression of $h b$ mRNA.

\section{Nanos is necessary for Pumilio-dependent para repression} The mechanism for translational repression of a majority of mRNAs by Pum requires the participation of the cofactor Nanos (Sonoda and Wharton, 1999; Kadyrova et al., 2007). Therefore, we tested whether this cofactor is also necessary for Pum to downregulate para mRNA and $I_{\mathrm{Na}}$. We overexpressed full-length Pum in a zygotic nanos ${ }^{17}$ homozygous mutant background. This mutation contains a single amino acid change in the C-terminal region of Nanos that is sufficient to influence embryonic segmentation presumably through disrupted translational repression of $h b$ mRNA (Curtis et al., 1997). nanos ${ }^{17}$ is a weak allele that produces embryos with variable numbers of abdominal segments and, although stronger nanos alleles have been described, nanos ${ }^{17}$ was chosen for this study because it produces viable first instar larvae. Whole-cell recordings from aCC/RP2 motoneurons in larvae overexpressing full-length Pum in a nanos ${ }^{17}$ mutant background failed to show a reduction in $I_{\mathrm{Na}}$ (Fig. $3 A, B$ ), indicative that Nanos is necessary for Pum-dependent repression of para mRNA. One copy of wild-type nanos in a heterozygous nanos ${ }^{17}$ mutant $\left(\right.$ nanos $\left.^{17} /+\right)$ rescues the ability of Pum to downregulate $I_{\mathrm{Na}}$. The extent of downregulation in the heterozygote is equivalent to that observed when two normal copies of nanos are present (i.e., wild type), suggesting that, although necessary, the dose of nanos does not determine the level of para repression (see also Fig. 5A). This represents another key difference between para and $h b$ repression in which Nanos is the principal factor limiting the translational repression of $h b$ mRNA by means of a posterior-toanterior concentration gradient (Barker et al., 1992). The nanos ${ }^{17}$ mutation alone does not show any differences in $I_{\mathrm{Na}}$ presumably because enough functional Nanos protein is present to allow endogenous Pum (but not increased Pum expression) to function normally (Fig. $3 A, B$ ). Quantification of para mRNA after panneuronal overexpression of Pum in the nanos ${ }^{17}$ mutant background also shows a clear necessity of Nanos for the downregulation of para mRNA (Fig. 3C). Thus, it would seem that, as for most Pum mRNA targets examined so far, translational repression of para requires the cofactor Nanos. However, it should be noted that this conclusion is based on the use of nanos ${ }^{17}$, which is a point mutation and not a genetic null.

\section{A requirement of Brain Tumor for para repression is cell type specific}

Brat is a second cofactor that is required for the translational repression of $h b$ mRNA (Sonoda and Wharton, 2001). To analyze the requirement of Brat in the translational regulation of para, we took advantage of UAS-pum ${ }^{\mathrm{G} 1330 \mathrm{D}}$, a single amino acid substitution that renders Pum unable to recruit Brat to the repression complex and, as such, unable to translationally repress $h b$ mRNA (Wharton et al., 1998). Patch-clamp analysis, after overexpression of UAS-pum ${ }^{\text {G1330D }}$ in aCC/RP2 motoneurons, shows normal $I_{\mathrm{Na}}$ (Fig. $4 A$ ), implicating that Brat binding is a necessary step for the downregulation of para in these neurons. However, para mRNA quantification from whole CNS after overexpression of UAS-pum ${ }^{\text {G1330D }}$ pan-neuronally suggests otherwise. This is be-
A

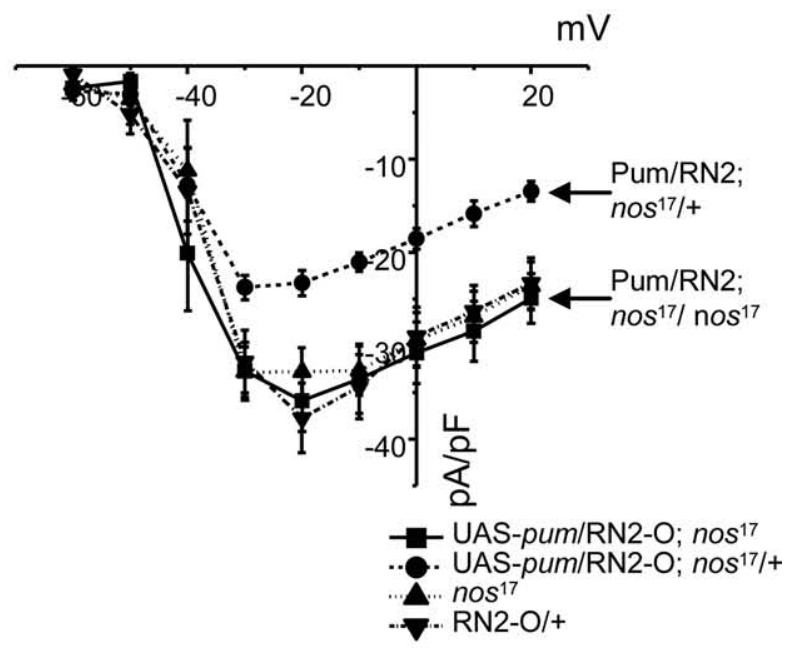

B

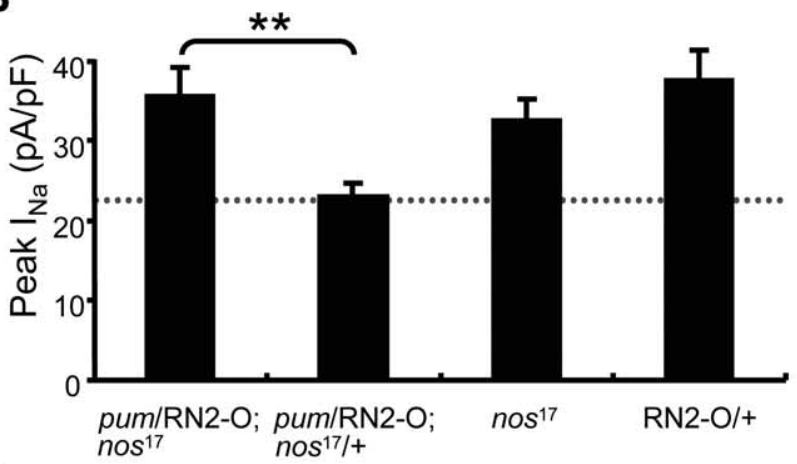

C

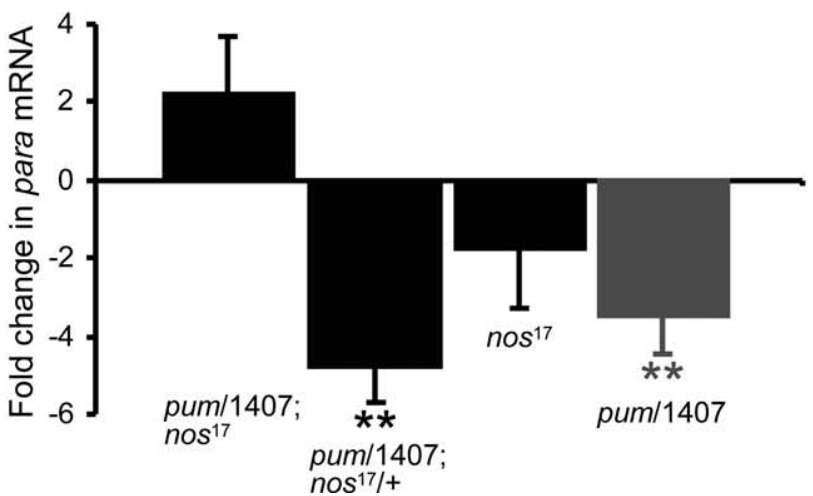

Figure 3. Nanos is necessary for Pumilio-dependent para repression. $\boldsymbol{A}$, Current-voltage plots of $I_{\mathrm{Na}}$ in aCC/RP2 comparing the following genotypes are shown: [UAS-pum/RN2-0; nanos ${ }^{17} /$ nanos ${ }^{17}$ ], [UAS-pum/RN2-0; nanos $^{17} /+$ ], $\left[\right.$ nanos $^{17} /$ nanos $^{17}$ ], and $[\mathrm{RN2} 2-0 /+$ ]. $\boldsymbol{B}$, Peak current amplitudes (measured at $-20 \mathrm{mV}$ ) show that overexpression of UAS-pum (FL) is unable to repress $I_{\mathrm{Na}}$ in a nanos ${ }^{17}$ homozygous background. Overexpression of UAS-pum in a nanos ${ }^{17}$ heterozygote is sufficient to repress $I_{\mathrm{Na}}(p=0.003$ compared with UAS-pum/RN2-0; nanos ${ }^{17}$ ). The nanos ${ }^{17}$ mutation alone does not affect $/ I_{\mathrm{Na}}$. Peak $I_{\mathrm{Na}}$ after overexpression of $p u m$ in a wild-type background is shown by the continuously dotted horizontal line. Values shown are as follows: $35.9 \pm 3.3,23.3 \pm 1.4,32.8 \pm 2.6$, and $37.7 \pm 3.7$, respectively. C, Real-time RT-PCR quantification of para mRNA for the same genotypes shown in part $\boldsymbol{B}$. Overexpression of pum in the absence of nanos fails to repress para mRNA levels (compared with 1407-GAL4 control). Values shown are as follows: $2.23 \pm 1.47,-4.80 \pm 0.87,-1.76 \pm 1.50$, and $-3.47 \pm 0.98$, respectively. For $\boldsymbol{A}$ and $\boldsymbol{B}$, values given are means $\pm \operatorname{SE}(n \geq 8)$. For $\boldsymbol{C}$, values given are means $\pm \mathrm{SE}(n \geq 4) .{ }^{* *} p \leq 0.01$.

cause para mRNA levels are still downregulated when UASpum $^{\mathrm{G} 1330 \mathrm{D}}$ is overexpressed in all neurons (Fig. $4 \mathrm{~B}$ ). This apparent dichotomy in requirement for Brat is consistent with the 

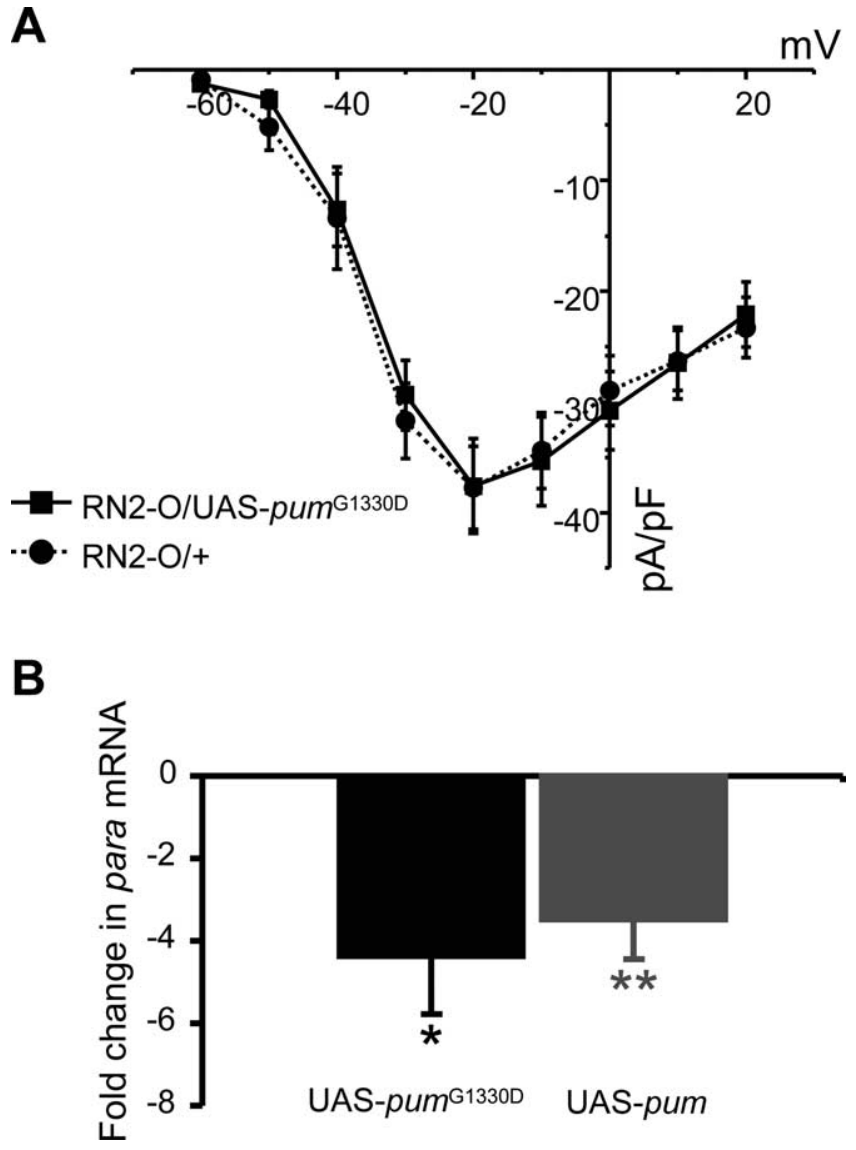

Figure 4. The requirement of Brat for para repression is cell type specific. $A$, Overexpression of UAS-pum ${ }^{61330 D}$ is unable to reduce $I_{\mathrm{Na}}$ in aCC/RP2 motoneurons. $B$, Real-time RT-PCR quantification of para mRNA shows a significant reduction after pan-neuronal overexpression of UAS-pum ${ }^{\text {G1330D }}$ using 1407-GAL4 ( $p \leq 0.05$ ). No significant differences exist between the overexpression of UAS-pum ${ }^{61330 D}$ and UAS-pum (gray; shown for comparative purposes). Values shown are as follows: $-4.39 \pm 1.34$ and $-3.47 \pm 0.98$, respectively. For $A$, values given are means $\pm \operatorname{SE}(n \geq 8)$. For $\boldsymbol{B}$, values given are means $\pm \operatorname{SE}(n \geq 4) .{ }^{*} p \leq 0.05 ;{ }^{* *} p \leq 0.01$.

majority of cells in the CNS not requiring Brat for the translational repression of para, whereas Pum-dependent repression of para mRNA in motoneurons is Brat dependent. Pum repression without Brat involvement has been already reported. $C y c B$ mRNA, a gene important for germ cell proliferation, is regulated by Pum and Nanos but does not require Brat (Kadyrova et al., 2007). In conclusion, our results are suggestive of Brat being necessary for Pum function in some cell types (i.e., aCC/RP2 motoneurons), but not in other types of neurons.

Pumilio is the limiting factor in para repression

A key factor for Pum-mediated repression of $h b$ mRNA in the Drosophila embryo is the spatial gradient of the cofactor Nanos. The posterior-to-anterior Nanos gradient defines the precise spatial zone of $h b$ mRNA translational repression. Pum, however, is distributed homogeneously throughout the embryo (Barker et al., 1992). To test whether Nanos was also limiting for repression of para mRNA, we overexpressed UAS-nanos in aCC/RP2 motoneurons and recorded $I_{\mathrm{Na}}$. No changes in $I_{\mathrm{Na}}$ were observed (Fig. 5A). Consistent with this observation, real-time RT-PCR quantification of para mRNA, after overexpression of nanos panneuronally, also showed no significant difference (Fig. 5B). Because our previous experiments demonstrate that the Pum protein is constitutively active [a mutation in pum results in an
A

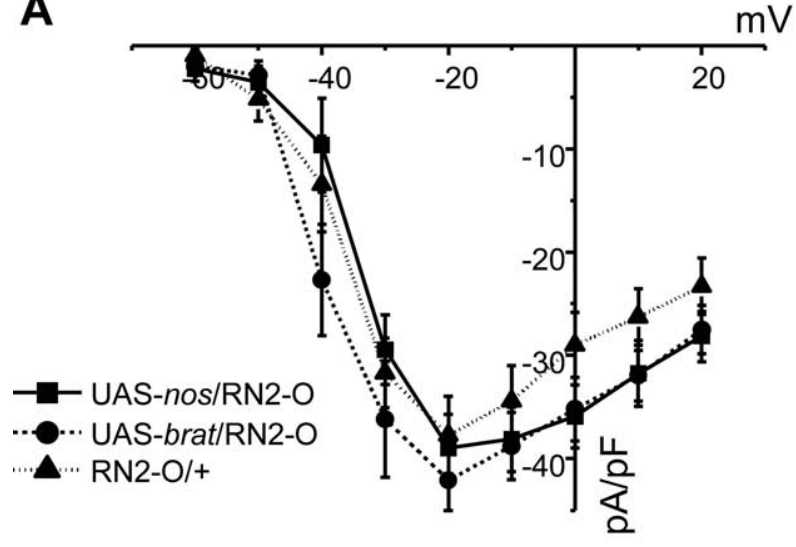

B

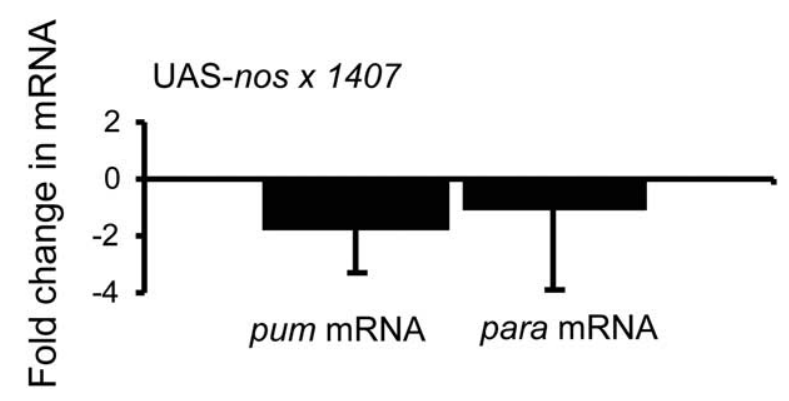

C

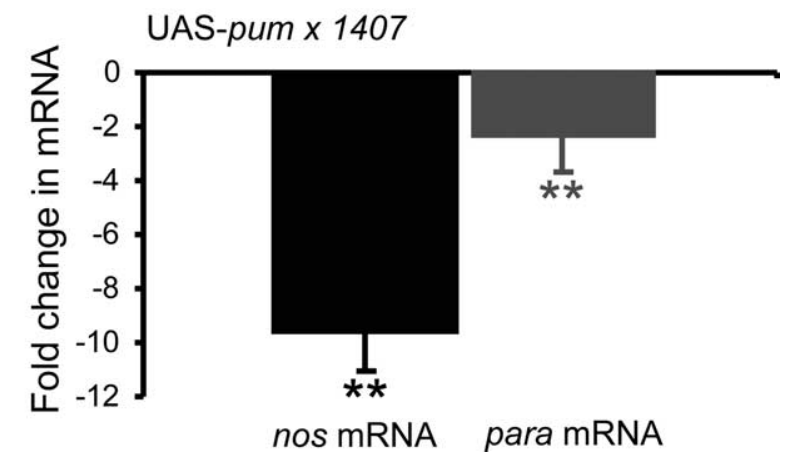

Figure 5. Pumilio is the limiting factor in para repression. $A$, Overexpression of either UASnanos or UAS-brat in aCC/RP2 motoneurons (using RN2-0-GAL4) does not affect $I_{\mathrm{Na}}$. $\boldsymbol{B}$, Panneuronal overexpression of UAS-nanos (1407-GAL4) is unable to significantly change levels of pum or para mRNA ( $p>0.05$ for both). Values shown are as follows: $-1.67 \pm 1.64$ and $-1.02 \pm 2.89$, respectively. C, Pan-neuronal overexpression of UAS-pum (FL) is sufficient to greatly reduce nanos mRNA ( $p<0.00001$ ) in addition to reducing para mRNA (gray; shown for comparative purposes). Values shown are as follows: $-9.56 \pm 1.53$ and $-3.47 \pm 0.98$, respectively. For $\boldsymbol{A}$, values given are means \pm SE $(n \geq 8)$. For $\boldsymbol{B}$ and $\boldsymbol{C}$, values given are means $\pm \mathrm{SE}(n \geq 4)$. ${ }^{* *} p \leq 0.01$.

increase in para mRNA (Mee et al., 2004)], our observation that overexpression of nanos is without effect is unlikely to be attributable to lack of functional Pum. These results, together with the fact that the nanos ${ }^{17}$ mutation alone does not affect the level of $I_{\mathrm{Na}}$ (Fig. 3), suggest that Nanos is not a limiting factor in para repression. Similarly, overexpression of brat does not produce a change in $I_{\mathrm{Na}}$ in aCC/RP2 (Fig. $5 A$ ). Therefore, given that $I_{\mathrm{Na}}$ in aCC/RP2 motoneurons is sensitive to Pum dosage (Fig. 2) (Mee et al., 2004), our data are consistent with Pum being a limiting factor for para mRNA translational repression in these neurons.

\section{Pumilio downregulates nanos}

To investigate further the Pum-dependent repression mechanism of para in the CNS, we examined whether Pum and Nanos 

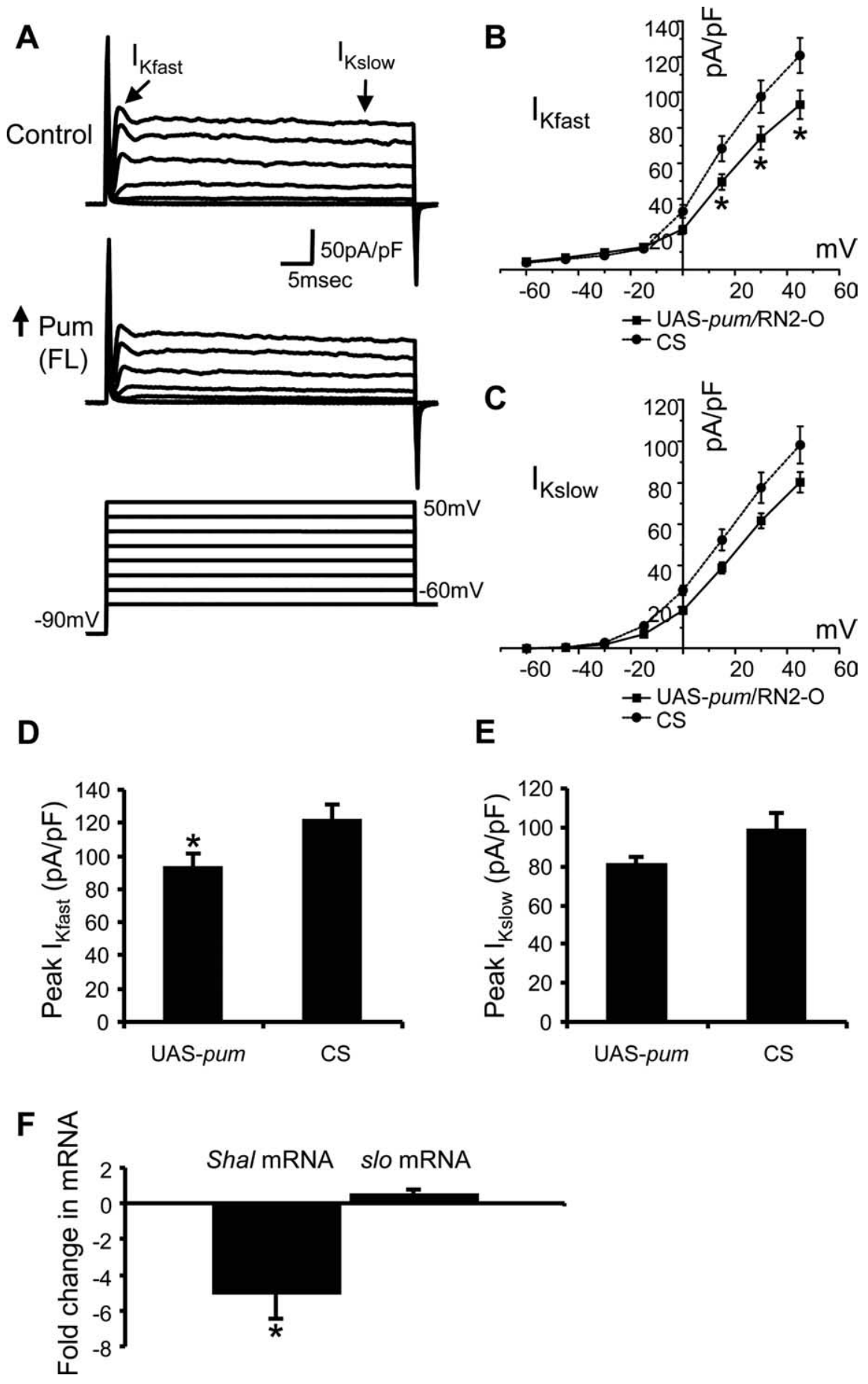

Figure 6. Pumilio negatively regulates $I_{\text {ffast }}$ and $S h a / m R N A$. $A$, Representative voltage- clamp recordings of voltage-gated $I_{\mathrm{K}}$ in aCC/RP2 motoneurons in control larvae (CS) (top trace) and after overexpression of pum (FL) (middle trace). The fast and slow components of $I_{K}$ in these motoneurons are indicated (arrows). Voltage protocol used to evoke $I_{K}$ is shown (bottom trace). $B, C$ Current-voltage plots for $I_{\text {Kfast }}$ and $I_{\text {Kslow }}$ measured after overexpression of UAS-pum and in control (CS). D, E, Peak current amplitudes (measured at $+45 \mathrm{mV}$ ) show that overexpression of UAS-pum results in a significant decrease in $I_{\text {Kfast }}(p=0.03)$ but not $I_{\text {Kslow. }}$ Values shown are as follows: $93.1 \pm 8.0$, and $120.8 \pm 9.9(\boldsymbol{D})$, and $80.2 \pm 4.9$, and $98.3 \pm 8.9(\boldsymbol{E})$, respectively. $\boldsymbol{F}$, Pan-neuronal overexpression of UAS-pum negatively regulates Shal mRNA ( $p=0.027)$, but not slo mRNA. Values shown are as follows: $-4.94 \pm 1.52$ and $0.41 \pm 0.31$, respectively. For $\boldsymbol{B}-\boldsymbol{E}$, values given are means $\pm \mathrm{SE}(n \geq 8)$. For $\boldsymbol{F}$, values given are means \pm SE $(n \geq 5) .{ }^{*} p \leq 0.05$.

could regulate one another. Such an interaction, if it exists, might be ideally suited to act as a control mechanism to safeguard neurons from excessive repression of para mRNA. Overexpression of UAS-nanos pan-neuronally does not produce any changes in pum mRNA levels (Fig. 5B). In contrast, overexpression of UAS-pum panneuronally resulted in a very large and significant decrease in nanos mRNA (Fig. $5 C$ ). The relative efficiency of Pum to downregulate nanos mRNA is approximately four times that of its ability to repress para mRNA. This regulation is possibly direct because binding of Pum to nanos mRNA has been reported (Gerber et al., 2006).

Pumilio indirectly regulates $I_{\text {Kfast }}$ and Shal mRNA

In the motoneurons under study, activitydependent homeostasis likely requires the coregulation of several proteins, including Pum, Para, and one or more $\mathrm{K}^{+}$channel proteins (Baines et al., 2001; Mee et al., 2004). Here, we showed that changes in $I_{\mathrm{Na}}$ current density are mediated by direct binding of Pum to para transcripts and subsequent translational repression. We therefore asked whether Pum can directly regulate transcript levels and ionic current densities of outward $\mathrm{K}^{+}$channels.

In the first instance, we looked at the effects of increased expression of Pum on potassium currents $\left(I_{\mathrm{K}}\right)$. In aCC/RP2 motoneurons $I_{\mathrm{K}}$ exhibits characteristic fast $\left(I_{\text {Kfast }}\right)$ and slow $\left(I_{\text {Kslow }}\right)$ inactivating phases (Fig. 6A) (Baines and Bate, 1998). Overexpression of full-length Pum, selectively in aCC/RP2 motoneurons, is sufficient to produce a significant decrease in the fast component of $I_{\mathrm{K}}$ in these neurons (Fig. 6B,D). In contrast, overexpression of Pum does not affect significantly the slow component (Fig. 6C,E). In Drosophila neurons, the fast component of $I_{\mathrm{K}}$ has been associated with the voltage-dependent potassium channel gene Shal (Shaker cognate I) (Tsunoda and Salkoff, 1995) and the voltage-dependent and calcium-activated potassium channel gene slowpoke (slo) (Pym et al., 2006). Therefore, we analyzed the effect of overexpression of Pum on both Shal and slo mRNA abundance. Realtime RT-PCR quantification shows significant diminution of Shal mRNA when Pum is overexpressed pan-neuronally, whereas slo mRNA levels are not affected (Fig. 6F).

Although we demonstrated that Pum can affect $I_{\text {Kfast }}$ in addition to $I_{\mathrm{Na}}$ in aCC/ RP2, we were unable to identify a consensus Pum binding sequence in the Shal transcript. Furthermore, our microarray analysis did not identify Shal mRNA as a direct target of Pum binding (A. Gerber and S. Luschnig, unpublished data). Because of this, it is conceivable that the effect of Pum on $I_{\mathrm{K}}$ may be an indirect consequence of a Pum-related reduction in $I_{\mathrm{Na}}$. This kind of compensatory mechanism has been 
A

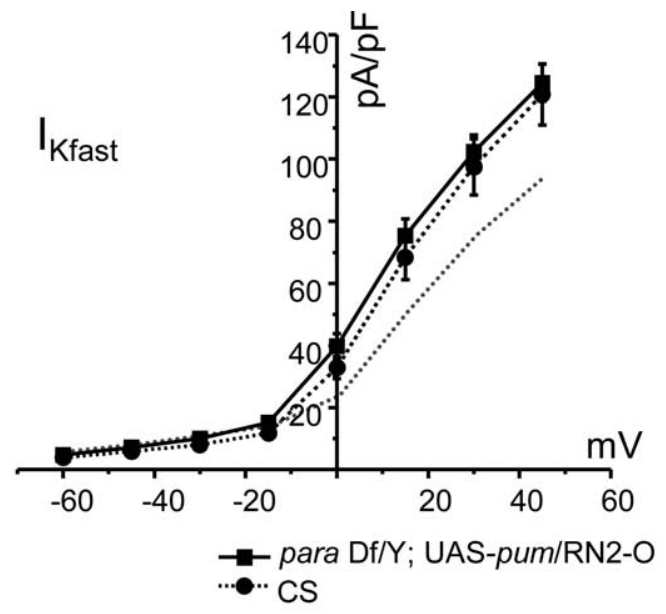

B

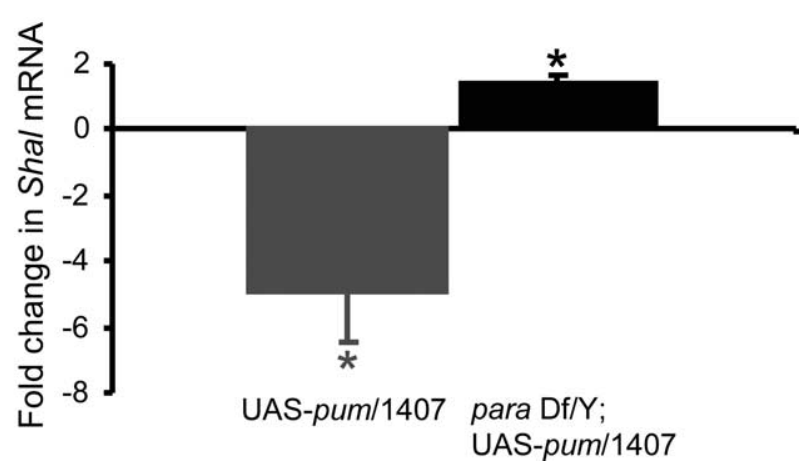

Figure 7. The effect of Pumilio on $I_{\text {Kfast }}$ is indirect. $A$, Overexpression of UAS-pum (RN2-0GAL4) in a para Dfbackground fails to reduce $I_{\text {Kfast }}$ compared with overexpression in a wild-type background (continuously dotted line). B, Pan-neuronal overexpression of UAS-pum in a para Df background also fails to reduce Shal mRNA compared with overexpression in a wild-type background (gray box). The baseline corresponds to 1407-GAL4 control. Values shown are as follows: $-4.94 \pm 1.52$ and $1.40 \pm 0.23$, respectively. For $A$, values given are means $\pm \mathrm{SE}$ $(n \geq 8)$. For $\boldsymbol{B}$, values given are means $\pm \operatorname{SE}(n \geq 4) .{ }^{*} p \leq 0.05$.

described previously (Baines et al., 2001). To test this, we overexpressed Pum in aCC/RP2 motoneurons in a genetic background bearing a deficiency chromosome for the para locus. The para deficiency causes late embryonic lethality, and, although embryos do not hatch, aCC/RP2 motoneuron recordings can still be performed (Baines and Bate, 1998). Overexpression of pum, in the complete absence of para, results in an $I_{\mathrm{K}}$ that is not significantly different than wild-type controls (Fig. 7A). Real-time RT-PCR quantification of Shal mRNA confirms our physiology. Thus, overexpression of pum pan-neuronally, in the absence of para, results in no downregulation of Shal mRNA. On the contrary, there is a small, but significant, increase in Shal mRNA under these conditions (Fig. $7 B$ ). We conclude, therefore, that the reduction in $I_{\text {Kfast }}$ and Shal observed when pum is overexpressed in wild-type backgrounds is most likely to be an indirect effect: Pum directly represses translation of para mRNA and this in turn produces a compensatory reduction of Shal mRNA abundance and $I_{\text {Kfast }}$.

\section{Discussion}

Identification of the molecular components that underlie homeostasis of membrane excitability in neurons remains a key challenge. Here, we show that the known translational repressor Pum binds para mRNA, which encodes the Drosophila voltagegated $\mathrm{Na}^{+}$channel. This observation provides a mechanistic understanding for the previously documented ability of Pum to regulate $I_{\mathrm{Na}}$ and membrane excitability in Drosophila motoneurons (Mee et al., 2004). Thus, alteration in activity of Pum, in response to changing exposure to synaptic excitation, enables neurons to continually reset membrane excitability through the translational control of a voltage-gated $\mathrm{Na}^{+}$channel.

Previous studies report several mRNAs subject to direct Pum regulation including $h b$ (Murata and Wharton, 1995), bicoid (bcd) (Gamberi et al., 2002), CycB (Asaoka-Taguchi et al., 1999), eIF4E (Menon et al., 2004), and possibly the transcript destabilization factor smaug (smg) (Tadros et al., 2007). The majority of these identified transcripts concentrate the roles of Pum to the establishment of the embryonic anterior-posterior axis $(h b$ and $b c d)$ and germ-line function/oogenesis $(C y c B)$. However, in the last few years, new findings have expanded the role of Pum to encompass predicted roles in memory formation, neuron dendrite morphology, and glutamate receptor expression in muscle (Dubnau et al., 2003; Menon et al., 2004; Ye et al., 2004). Indeed, the role of Pum is likely to be very much more widespread given that Pum pull-down assays followed by microarray analysis of bound mRNAs have now identified a plethora of possible additional targets of translational regulation (Gerber et al., 2006). The $\sim 1000$ or so genes identified are implicated to be involved in various cellular functions, suggesting that Pum-dependent translational repression might be a mechanism used in different stages of development and in diverse tissue function. To date, para is the first confirmed Pum target encoding a voltage-gated ion channel.

Pum-binding motifs have been identified in the $3^{\prime}$-UTRs of many mRNAs known to bind to this protein. Analysis of $113 \mathrm{such}$ genes expressed in adult Drosophila ovaries has identified a consensus 8 nt binding motif [UGUAHAUA (Gerber et al., 2006)]. This sequence contains the UGUA tetranucleotide that is a defining characteristic of the NRE-like motif described in the $3^{\prime}$-UTR of $h b$ mRNA (Zamore et al., 1997). We identified such an $8 \mathrm{nt}$ motif within the ORF of para at the $3^{\prime}$ end of the transcript. Our biochemical binding data support the notion that this motif is indeed sufficient to bind Pum and as such represents the first such site to be localized to an ORF of any transcript. However, to translationally repress para mRNA, our data also show a requirement for regions of Pum in addition to the RBD. Interestingly, this kind of requirement has also been shown for another Pum target, eIF4E (Menon et al., 2004). The translational silencing of mRNAs is a complex mechanism on which only little information is available. It could involve deadenylation and degradation of the mRNA and/or the circularization of the mRNA and the recruitment of factors that would preclude translation (Chagnovich and Lehmann, 2001). The fact that different Pum targets may require only the RBD $(h b)$ or the full-length protein (eIF4E and para) suggests that Pum-mediated translational repression may follow complex target mRNA-specific mechanisms, most probably involving the interaction of other domains of Pum with additional, so far unknown, factors. In this regard, it is interesting to note that the $\mathrm{N}$ terminus of Pum has regions of low complexity including prion-like domains rich in $\mathrm{Q} / \mathrm{R}$. These domains may provide a platform for other proteins that influence the fate of Pum targets.

The putative Pum binding motif that we identify lies within an exon that is common to all para splice variants identified (at least in the embryo) but is possibly subject to editing by adenosine deamination. Thus, in an analysis of splicing of para, a number of individual cDNA clones were sequenced and one splice variant was recovered that shows A-to-I editing in this motif (D. E. Wright and R. A. Baines, unpublished data). Together with a differential requirement for specific cofactors (see below), editing 
of this motif might serve to influence how para is affected by Pum and, as such, further increase diversity in level of expression of $I_{\mathrm{Na}}$ in differing neurons or disease states (Song et al., 2004).

The known mechanism of action of Pum-dependent translational repression is absolutely dependent on additional cofactors. The most studied example, that of $h b$ mRNA during early embryogenesis, requires the presence of both Nanos (Sonoda and Wharton, 1999) and Brat (Sonoda and Wharton, 2001). However, the requirement for these two cofactors is seemingly transcript dependent. Thus, Pum-mediated repression of $C y c B$ mRNA requires Nanos but not Brat (Sonoda and Wharton, 2001). However, Pum-dependent repression of $b c d$ is apparently Nanos independent, because levels of Nanos in the anterior of the early embryo are undetectable (Gamberi et al., 2002). Although we clearly show that Pum-dependent repression of para mRNA in the Drosophila CNS requires Nanos, the requirement for Brat is less clear and seems to be neuronal cell type specific. A requirement for a different combination of cofactors for Pumdependent translational regulation of a single gene transcript has not been reported previously, but clearly might represent an additional level of regulation. Such differential regulation might be required to spatially restrict the effect of Pum to certain cell types within the CNS. Voltage-gated $\mathrm{Na}^{+}$currents are responsible for the initiation and propagation of the action potential and determine, together with other voltage-gated ion conductances, the membrane excitability of a neuron. Despite para being the sole voltage-gated sodium channel gene in Drosophila [compared with at least nine different genes in mammals (Catterall et al., 2005)], neuronal subpopulations nevertheless exhibit distinctive $I_{\mathrm{Na}}$ characteristics (O'Dowd et al., 1995) (N. Muraro and R. Baines, unpublished observations). To achieve this, para is known to undergo extensive alternative splicing (Thackeray and Ganetzky, 1994; Thackeray and Ganetzky, 1995) and, additionally, RNA editing (Hanrahan et al., 2000). It is highly likely that both alternative splicing and RNA editing generate mRNAs that encode channels with differing electrophysiological properties (Song et al., 2004). It is also conceivable that these mechanisms might yield para transcripts that contain differing arrangements of Pum/Nanos binding sites, which may, or may not, recruit Brat. Indeed, it has been proposed that variations of the NRE consensus sequence may result in Pum-NRE-Nanos complexes with different topographies, resulting in altered recruitment abilities for additional cofactors such as Brat (Kadyrova et al., 2007). Additional work is necessary to clarify where, in para mRNA, the binding sites for the Pum/Nanos complex are localized and how the recruitment of Brat is facilitated in only some neurons. In the $h b$ repression complex, Brat has been shown to interact with the cap-binding protein d4EHP (Cho et al., 2006). Therefore, additional cofactors might be necessary for Pum-dependent para repression in the Brat-independent neuronal cell subtypes that we propose here.

In contrast to translational repression of $h b$, our data show that Nanos is unlikely to be a limiting factor of Pum-dependent repression of para translation. Consistent with this finding is our observation that overexpression of pum is sufficient to downregulate (and probably translationally repress) nanos mRNA. However, the opposite is not true; overexpression of nanos does not affect levels of pum mRNA. These data suggest that Pum is at least a principal orchestrating factor (if not the prime factor) in regulation of para translation. Moreover, our demonstration that overexpression of pum is sufficient to greatly downregulate nanos mRNA (relative to para mRNA), together with a requirement of Nanos for Pum-dependent para mRNA repression, implicates the existence of a protective negative-feedback mechanism that prevents overrepression of para mRNA. In the absence of such feedback, it is conceivable that excessive overrepression of para mRNA might lead to neurons falling silent as their membrane excitability drops below a critical threshold. Were this to happen, then signaling in the affected neuronal circuit would be severely compromised.

We show that overexpression of full-length Pum in aCC/RP2 motoneurons not only causes a decrease in $I_{\mathrm{Na}}$ but also a significant decrease in $I_{\text {Kfast }}$. Additionally, pan-neuronal overexpression of Pum causes a significant decrease in Shal mRNA, a gene encoding a potassium channel known to contribute to $I_{\text {Kfast }}$ (Tsunoda and Salkoff, 1995). This result was surprising given that we did not identify Shal as a Pum target from our microarray analysis (A. P. Gerber and S. Luschnig, unpublished results). That this mechanism might, therefore, be indirect is corroborated by our finding that $I_{\text {Kfast }}$ and Shal mRNA remain at wild-type levels when Pum is overexpressed in a para-null background. It is, perhaps, counterintuitive that a reduction in $I_{\mathrm{Na}}$, to achieve a reduction in membrane excitability, should be accompanied by a similar decrease in outward $I_{\text {Kfast }}$. However, changes in ionic conductances should not be considered in isolation and such a relationship might serve to maintain action potential kinetics within physiological constraints (Baines, 2003). Covariation of $I_{\mathrm{Na}}$ and $I_{\mathrm{K}}$ as a mechanism for changing neuronal excitability has been described in these motoneurons previously (Baines et al., 2001). Moreover, there is precedent for coupling between transcripts: injection of Shal mRNA into lobster PD (pyloric dilator) neurons results in an expected increase in $I_{\mathrm{A}}$ but also an unexpected linearly correlated increase in $I_{\mathrm{h}}$, an effect that acts to preserve membrane excitability. Injection of a mutated, nonfunctional, Shal mRNA is also sufficient to increase $I_{\mathrm{h}}$ indicative that this coregulation is activity independent (MacLean et al., 2003). It remains to be shown whether genetic manipulation of para mRNA levels in Drosophila motoneurons will similarly evoke compensatory changes in Shal expression.

In a previous study, it was shown that blockade of synaptic release, through pan-neuronal expression of tetanus toxin light chain, was sufficient to evoke a compensatory increase in membrane excitability in aCC/RP2 that was accompanied by increases in $I_{\mathrm{Na}}, I_{\text {Kfast }}$, and also $I_{\text {Kslow }}$ (Baines et al., 2001). In contrast, we show here that overexpression of pum is sufficient to decrease $I_{\mathrm{Na}}$ and $I_{\text {Kfast }}$ but does not significantly affect $I_{\text {Kslow }}$ (although there is a small nonsignificant reduction in this current). Clearly, the complete absence of synaptic input is a more severe change that likely elicits a greater compensatory change in these neurons than when Pum is overexpressed. However, whether removal of synaptic excitation also invokes additional compensatory mechanisms that act preferentially on $I_{\text {Kslow }}$ remains to be determined. What is consistent, however, is that change in synaptic excitation of these motoneurons is countered by Pum-dependent regulation of both para mRNA translation and magnitude of $I_{\mathrm{Na}}$.

A key question remains as to what the mechanism is that transduces changes in synaptic excitation to altered Pum activity. Perhaps the most parsimonious mechanism will be one linked to influx of extracellular $\mathrm{Ca}^{2+}$. Indeed, experimental evidence supports a role for $\mathrm{Ca}^{2+}$, because blocking its entry can preclude changes in neuronal excitability observed as a result of activity manipulation (Offord and Catterall, 1989; Desarmenien and Spitzer, 1991; Golowasch et al., 1999). In addition, changes of gene expression resulting from activity-mediated $\mathrm{Ca}^{2+}$ entry have been described both in vitro (Xiang et al., 2007) and in vivo after plasticity changes such as long-term potentiation (Miy- 
amoto, 2006). Whether $\mathrm{Ca}^{2+}$ influx influences translation and/or transcription of Pum remains to be shown. Stimulation of mammalian neurons in culture with glutamate, after a preconditioning period of forced quiescence, results in an increase of Pum2 protein levels after just 10 min (Vessey et al., 2006). The rapidity of this response suggests that it is mediated by a posttranscriptional mechanism. We examined the role of Pum on $\mathrm{Ca}^{2+}$ channel activity. We find that neither $I_{\mathrm{Ba}(\mathrm{Ca})}$ nor levels of the voltage-gated calcium channel coded by DmcalA (cacophony, Calcium channel $\alpha 1$ subunit, type $A$ ) (Peng and $\mathrm{Wu}, 2007$ ) are affected in aCC/RP2 motoneurons in which pum [full length (FL)] is overexpressed (data not shown). The fact that Pum does not affect $\mathrm{Ca}^{2+}$ channel activity directly could reinforce the idea of its serving as a primary sensor of activity changes.

In summary, we show that Pum is able to bind to para mRNA, an effect that we previously showed to be sufficient to regulate both $I_{\mathrm{Na}}$ and membrane excitability in Drosophila motoneurons (Mee et al., 2004). This mechanism requires the cofactor Nanos but does not obligatorily require Brat. Given that mammals express two Pum genes, Pum1 and Pum2 (Spassov and Jurecic, 2002), it will be of importance to determine whether this protein is also able to regulate sodium channel translation in the mammalian CNS.

\section{References}

Asaoka-Taguchi M, Yamada M, Nakamura A, Hanyu K, Kobayashi S (1999) Maternal Pumilio acts together with Nanos in germline development in Drosophila embryos. Nat Cell Biol 1:431-437.

Baines RA (2003) Postsynaptic protein kinase A reduces neuronal excitability in response to increased synaptic excitation in the Drosophila CNS. J Neurosci 23:8664-8672.

Baines RA, Bate M (1998) Electrophysiological development of central neurons in the Drosophila embryo. J Neurosci 18:4673-4683.

Baines RA, Uhler JP, Thompson A, Sweeney ST, Bate M (2001) Altered electrical properties in Drosophila neurons developing without synaptic transmission. J Neurosci 21:1523-1531.

Barker DD, Wang C, Moore J, Dickinson LK, Lehmann R (1992) Pumilio is essential for function but not for distribution of the Drosophila abdominal determinant Nanos. Genes Dev 6:2312-2326.

Brand AH, Perrimon N (1993) Targeted gene expression as a means of altering cell fates and generating dominant phenotypes. Development 118:401-415.

Catterall WA, Goldin AL, Waxman SG (2005) International Union of Pharmacology. XLVII. Nomenclature and structure-function relationships of voltage-gated sodium channels. Pharmacol Rev 57:397-409.

Chagnovich D, Lehmann R (2001) Poly(A)-independent regulation of maternal hunchback translation in the Drosophila embryo. Proc Natl Acad Sci USA 98:11359-11364.

Cho PF, Gamberi C, Cho-Park YA, Cho-Park IB, Lasko P, Sonenberg N (2006) Cap-dependent translational inhibition establishes two opposing morphogen gradients in Drosophila embryos. Curr Biol 16:2035-2041.

Curtis D, Treiber DK, Tao F, Zamore PD, Williamson JR, Lehmann R (1997) A CCHC metal-binding domain in Nanos is essential for translational regulation. EMBO J 16:834-843.

Davis GW (2006) Homeostatic control of neural activity: from phenomenology to molecular design. Annu Rev Neurosci 29:307-323.

Desai NS, Rutherford LC, Turrigiano GG (1999) Plasticity in the intrinsic excitability of cortical pyramidal neurons. Nat Neurosci 2:515-520.

Desarmenien MG, Spitzer NC (1991) Role of calcium and protein kinase C in development of the delayed rectifier potassium current in Xenopus spinal neurons. Neuron 7:797-805.

Dubnau J, Chiang AS, Grady L, Barditch J, Gossweiler S, McNeil J, Smith P, Buldoc F, Scott R, Certa U, Broger C, Tully T (2003) The staufen/pumilio pathway is involved in Drosophila long-term memory. Curr Biol 13:286-296.

Frank DJ, Edgar BA, Roth MB (2002) The Drosophila melanogaster gene brain tumor negatively regulates cell growth and ribosomal RNA synthesis. Development 129:399-407.

Fujioka M, Emi-Sarker Y, Yusibova GL, Goto T, Jaynes JB (1999) Analysis of an even-skipped rescue transgene reveals both composite and discrete neuronal and early blastoderm enhancers, and multi-stripe positioning by gap gene repressor gradients. Development 126:2527-2538.

Gamberi C, Peterson DS, He L, Gottlieb E (2002) An anterior function for the Drosophila posterior determinant Pumilio. Development 129:2699-2710.

Gerber AP, Luschnig S, Krasnow MA, Brown PO, Herschlag D (2006) Genome-wide identification of mRNAs associated with the translational regulator PUMILIO in Drosophila melanogaster. Proc Natl Acad Sci USA 103:4487-4492.

Golowasch J, Abbott LF, Marder E (1999) Activity-dependent regulation of potassium currents in an identified neuron of the stomatogastric ganglion of the crab Cancer borealis. J Neurosci 19:RC33(1-5).

Hanrahan CJ, Palladino MJ, Ganetzky B, Reenan RA (2000) RNA editing of the Drosophila para $\mathrm{Na}^{+}$channel transcript. Evolutionary conservation and developmental regulation. Genetics 155:1149-1160.

Kadyrova LY, Habara Y, Lee TH, Wharton RP (2007) Translational control of maternal Cyclin B mRNA by Nanos in the Drosophila germline. Development 134:1519-1527.

MacLean JN, Zhang Y, Johnson BR, Harris-Warrick RM (2003) Activityindependent homeostasis in rhythmically active neurons. Neuron 37:109-120.

Marder E, Prinz AA (2002) Modeling stability in neuron and network function: the role of activity in homeostasis. BioEssays 24:1145-1154.

Mee CJ, Pym EC, Moffat KG, Baines RA (2004) Regulation of neuronal excitability through pumilio-dependent control of a sodium channel gene. J Neurosci 24:8695-8703.

Menon KP, Sanyal S, Habara Y, Sanchez R, Wharton RP, Ramaswami M, Zinn K (2004) The translational repressor Pumilio regulates presynaptic morphology and controls postsynaptic accumulation of translation factor eIF-4E. Neuron 44:663-676.

Miyamoto E (2006) Molecular mechanism of neuronal plasticity: induction and maintenance of long-term potentiation in the hippocampus. J Pharmacol Sci 100:433-442.

Murata Y, Wharton RP (1995) Binding of pumilio to maternal hunchback mRNA is required for posterior patterning in Drosophila embryos. Cell 80:747-756.

O’Dowd DK, Gee JR, Smith MA (1995) Sodium current density correlates with expression of specific alternatively spliced sodium channel mRNAs in single neurons. J Neurosci 15:4005-4012.

Offord J, Catterall WA (1989) Electrical activity, cAMP, and cytosolic calcium regulate mRNA encoding sodium channel alpha subunits in rat muscle cells. Neuron 2:1447-1452.

Peng IF, Wu CF (2007) Drosophila cacophony channels: a major mediator of neuronal $\mathrm{Ca}^{2+}$ currents and a trigger for $\mathrm{K}^{+}$channel homeostatic regulation. J Neurosci 27:1072-1081.

Pym EC, Southall TD, Mee CJ, Brand AH, Baines RA (2006) The homeobox transcription factor Even-skipped regulates acquisition of electrical properties in Drosophila neurons. Neural Develop 1:3.

Schweers BA, Walters KJ, Stern M (2002) The Drosophila melanogaster translational repressor pumilio regulates neuronal excitability. Genetics 161:1177-1185.

Song W, Liu Z, Tan J, Nomura Y, Dong K (2004) RNA editing generates tissue-specific sodium channels with distinct gating properties. J Biol Chem 279:32554-32561.

Sonoda J, Wharton RP (1999) Recruitment of Nanos to hunchback mRNA by Pumilio. Genes Dev 13:2704-2712.

Sonoda J, Wharton RP (2001) Drosophila Brain Tumor is a translational repressor. Genes Dev 15:762-773.

Spassov DS, Jurecic R (2002) Cloning and comparative sequence analysis of PUM1 and PUM2 genes, human members of the Pumilio family of RNAbinding proteins. Gene 299:195-204.

Tadros W, Goldman AL, Babak T, Menzies F, Vardy L, Orr-Weaver T, Hughes TR, Westwood JT, Smibert CA, Lipshitz HD (2007) SMAUG is a major regulator of maternal mRNA destabilization in Drosophila and its translation is activated by the PAN GU kinase. Dev Cell 12:143-155.

Thackeray JR, Ganetzky B (1994) Developmentally regulated alternative splicing generates a complex array of Drosophila para sodium channel isoforms. J Neurosci 14:2569-2578.

Thackeray JR, Ganetzky B (1995) Conserved alternative splicing patterns and splicing signals in the Drosophila sodium channel gene para. Genetics 141:203-214. 
Tsunoda S, Salkoff L (1995) Genetic analysis of Drosophila neurons: Shal, Shaw, and Shab encode most embryonic potassium currents. J Neurosci 15:1741-1754.

Turrigiano GG (1999) Homeostatic plasticity in neuronal networks: the more things change, the more they stay the same. Trends Neurosci 22:221-227.

Turrigiano GG, Nelson SB (2000) Hebb and homeostasis in neuronal plasticity. Curr Opin Neurobiol 10:358-364.

Vessey JP, Vaccani A, Xie Y, Dahm R, Karra D, Kiebler MA, Macchi P (2006) Dendritic localization of the translational repressor Pumilio 2 and its contribution to dendritic stress granules. J Neurosci 26:6496-6508.

Wharton RP, Sonoda J, Lee T, Patterson M, Murata Y (1998) The Pumilio RNA-binding domain is also a translational regulator. Mol Cell
1:863-872.

Wickens M, Bernstein DS, Kimble J, Parker R (2002) A PUF family portrait: 3'UTR regulation as a way of life. Trends Genet 18:150-157.

Xiang G, Pan L, Xing W, Zhang L, Huang L, Yu J, Zhang R, Wu J, Cheng J, Zhou Y (2007) Identification of activity-dependent gene expression profiles reveals specific subsets of genes induced by different routes of $\mathrm{Ca}^{2+}$ entry in cultured rat cortical neurons. J Cell Physiol 212:126-136.

Ye B, Petritsch C, Clark IE, Gavis ER, Jan LY, Jan YN (2004) Nanos and Pumilio are essential for dendrite morphogenesis in Drosophila peripheral neurons. Curr Biol 14:314-321.

Zamore PD, Williamson JR, Lehmann R (1997) The Pumilio protein binds RNA through a conserved domain that defines a new class of RNAbinding proteins. RNA 3:1421-1433. 